\title{
湿式球形造粒における平衡造粒粒子径の検討
}

\section{Equilibrium Agglomerate Diameter in Wet Spherical Agglomeration}

\author{
高 瀬均, 小路口 正 志 \\ Hitoshi TAKASE, Tadashi SHOJIGUCHI
}

\begin{abstract}
Equilibrium agglomerate diameter in wet spherical agglomeration was investigated at various concentrations of added surface active agent and the addition ratios of bridging liquid. Spherical polyethylene particles, castor oil and sodium oleate were used respectively as the raw particles, the bridging liquid and the surface active agent. The addition of surface active agent to disperse medium modified both the interfacial tension between bridging liquid and disperse medium and the contact angle of bridging liquid on raw particles, and therefore affected the agglomeration phenomena. The relationship between the equilibrium agglomerate diameter and the factors affecting wet spherical agglomeration was well explained by the theoretical model, which takes into account the balance between the cohesive force by capillary suction potential and the destructive force by agitation.
\end{abstract}

Key Words : Equilibrium Agglomerate Diameter, Wet Spherical Agglomeration, Capillary Suction Potential, Contact Angle, Saturation

\section{1. 緒言}

湿式球形造粒では，分散媒に不溶性で懸濁粒子には 親和性を有する架橋剂を䀣濁液中に添加して擋找し， 液中で懸濁粒子が造粒される。造粒現象が起きる原因 は, 粒子間に架橋剂が付着して液体架橋が形成される ことによって働く毛管吸引圧である。

湿式球形造粒において，形成される造粒粒子の大き さは，造粒粒子の製造"゙のものが目的である場合だ けでなく， 選択造粒 ${ }^{2 \sim 31}$ 後の目的成分の分離の容易 さ, 造粒を利用したろ過, 脱水操作 ${ }^{4)}$ の良否などにも 大きく影響を与える重要な事項である。

このため，これまで湿式球形造粒による造粒粒子径 については，毛管吸引圧に関係する各種の要因，擋拌 強度の影響などの面から，様々な検討がなされてい る。この内, 造粒粒子径への毛管吸引圧に関係する要 因の影響については，架橋剂／分散媒間の界面張力, 架橋剂の試料粒子に対する接触角，造粒粒子中の間隙 率および架橋剤の飽和度, 試料粒子径などの影響につ いて研究報告 ${ }^{5 \sim 9)}$ がなされている。これらの各要因

\footnotetext{
1999 年 10 月 22 日受付

富山大学工学部物質生命システム工学科

（テ930-8555 富山市五福3190）TEL 076-445-6830

Department of Material Systems Engineering and Life

Science. Toyama University

(3190 Gofuku, Toyama 930-8555)
}

は，毛管吸引压に影響する全要因を網羅していると言 える。しかし，個々の研究報告においては，接触角や 架橋剂飽和度の影響が考慮されていなかったり，試料 粒子の代表径だけを示し，粒子径の分布幅については 明示されていないものも多い。粒子径の分布幅の大小 は，毛管吸引压に影響することが知られており ${ }^{101}$ ，こ れより試料粒子の粒子径分布を常に明らかにしておく 必要がある。また, 従来の研究では, 試料粒子に対す る架橋剂の接触角が, 同材料の平板や試料粒子の成形 体に対する静的な条件下で行われた測定結果をもとに 求められている。このような接触角の值が, 造粒器内 での様々な外力を受ける動的な状況下での試料粒子に 対する架橋剂の接触角を, どの程度再現しているかに ついては問題のある所である。

本研究は, 湿式球形造粒の平衡造粒粒子径に及ぼす 毛管吸引压の大きさの影響について，球形のモデル粒 子を用いて実験的に検討したものである。毛管吸引压 の值をこれに影響する全ての要因の測定を行い，そ の結果をもとに算出した。特に，試料粒子に対する架 橋剂の接触角測定においては，造粒操作下での接触角 值により近い值を得るため，造粒粒子中の試料粒子間 の液体架橋部の拡大画像から直接接触角を求めた。平 衡造粒粒子径の大きさは，毛管吸引压が働くことによ る造粒粒子内の凝集力と，造粒粒子に㗢く破壊力との 釣り合いの観点から検討された。 


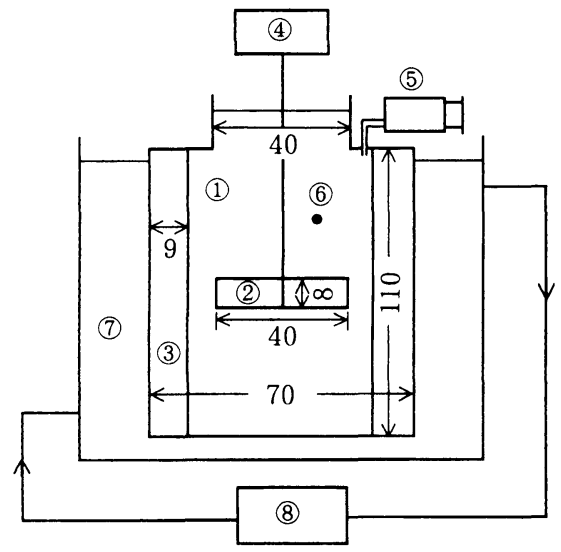

(1) Agglomeration tank (2) Impeller (3) Baffle (4) Motor (5) Injector (6) Sampling point (7) Jacket (8) Thermoregulator

Fig. 1 Schematic diagram of experimental apparatus (unit : $\mathrm{mm}$ )

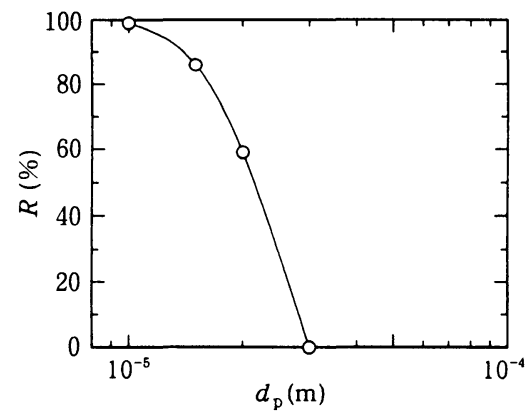

Fig. 2 Particle size distribution of polyethylene particle

\section{2. 実験方法}

\section{1 造粒操作}

湿式球形造粒を，Fig. 1 に示す内径 $70 \mathrm{~mm}$ の円筒 型摚汼槽造粒器内で行った。擋拌翼は櫂型 4 枚羽根 で, 造粒器内壁には邪魔板が 4 枚設けられている。試 料粒子として, 粒度のそろった分子量が $2 \times 10^{6}$ の球 形ポリエチレン粒子を用いた。Fig. 2 に，遠心沈降式 粒度分布測定装置（島津製作所製，SA-CP3）で測定 したポリエチレン粒子の粒子径分布を示す。試料粒子 を造粒器内の分散媒中に $5 \mathrm{vol} \%$ の濃度で懸濁させ, 30 分間摚拌の後, 注射器を使って架橋剂であるひま し油を 10 秒間で懸濁液中に添加した。架橋剂添加開 始時を造粒時間 $t_{\mathrm{a}}=0 \mathrm{~min}$ とし, 最長造粒時間を 60 分間とした。擋拌速度を $25 \mathrm{~s}^{-1}$ とし, 造粒器内温度
Table 1 Properties of polyethylene particle and castor oil (at $30^{\circ} \mathrm{C}$ )

\begin{tabular}{|c|c|c|}
\hline \multicolumn{3}{|c|}{ Polyethylene particle } \\
\hline$d_{\mathrm{p} ; 0}(\mathrm{~m})$ & $d_{\mathrm{ps}}(\mathrm{m})$ & $\rho_{\mathrm{p}}\left(\mathrm{kg} \cdot \mathrm{m}^{-3}\right)$ \\
\hline $2.15 \times 10^{-5}$ & $2.26 \times 10^{-5}$ & $9.40 \times 10^{2}$ \\
\hline \multicolumn{3}{|l|}{ Castor oil } \\
\hline$\rho_{\mathrm{o}}\left(\mathrm{kg} \cdot \mathrm{m}^{-3}\right)$ & $\mu_{0}(\mathrm{~Pa} \cdot \mathrm{s})$ & \\
\hline $9.50 \times 10^{2}$ & 0.51 & \\
\hline
\end{tabular}

を $30{ }^{\circ} \mathrm{C}$ とした。分散媒として $0.01 \mathrm{~mol} \cdot l^{-1}-\mathrm{NaCl}$ 水溶液を用い, 添加界面活性剂としてオレイン酸ナ トリウムを用いた。試料粒子に対する添加架橋剂の 容積比である架橋剤添加率 $r$ を, $0.1 \sim 0.4$ の範囲内 で変えた。造粒現象が起こる場合には， $t_{\mathrm{a}}=60 \mathrm{~min}$ において分散媒中に残留している架橋剤は見られなか った。Table 1に，ポリエチレン粒子，ひまし油の物 性を示す。

任意の造粒時間において造粒器内から懸濁液を $3 \mathrm{~m} l$ ずつ採取し, 乾燥器内へ入れて㲘濁液中の水分 を蒸発させた後, 篩分けにより造粒粒子の粒子径分布 を測定した。

\section{2 各種測定法}

\section{2.1 界面張力}

分散媒とひまし油との間の界面張力 $\gamma_{\text {ow }}$ を懸滴法 ${ }^{11}$ により測定した。測定に用いた分散媒は，2．1で調 整した分散媒中で $5 \mathrm{vol} \%$ の濃度の試料粒子を 30 分間 擋找した後, ガラス䄉維フィルター (ADVANTEC 社 製，GF75）により固液分離して得られた分離液であ る。測定手順は，まず上部の開いた直方体の透明容器 に分散媒を入れ，その中にひまし油を入れた注射器の 針の先端部を浸した。透明容器内は $30^{\circ} \mathrm{C} に$ 保たれ た。針はコの字型になっており, 先端の開口部は垂直 に上を向いている。この開口部よりひまし油を出して 滴を作った。分散媒との密度差により, 滴は上方に伸 びた形状となる。2 分間静置後, 滴の真横から顕微鏡 付きカメラにより，滴形状を拡大した写真を撮った。 この写真によりひまし油滴の各部の寸法を測定し, こ れらの值をもとに界面張力を算出した。

\section{2.2 接触角}

造粒時間 $t_{\mathrm{a}}=60 \mathrm{~min}$ において, 造粒器内より造粒 粒子を含む䀣濁液を採取し，これをスライドガラス上 に滴下させ，この上にカバーガラスをかぶせた。顕微 鏡によりスライドガラス上の造粒粒子を拡大し，試料 粒子間に形成された架橋剂による液体架橋部を, カメ ラにより撮影した。Fig. 3 （a）に，撮影された液体架 
(a)

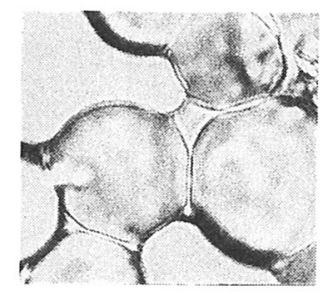

(b)

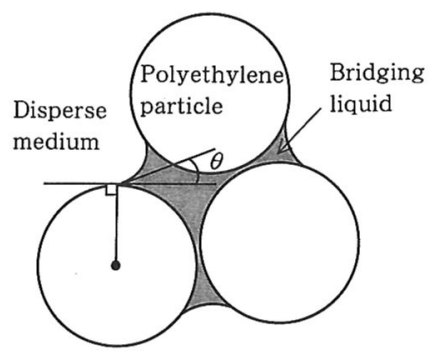

Fig. 3 Contact angle of bridging liquid on polyethylene particle

(a) photograph of liquid bridge between polyethylene particles $\left(r=0.35, C_{\text {ole }}=0 \mathrm{~mol} \cdot l^{-1}\right)$

(b) measurement of contact angle $\theta$

橋部の例を示す。分散媒中における架橋剂の試料粒子 表面に対する接触角 $\theta$ を, Fig. 3 (b) に示す作図法に より求めた。

\section{2.3 造粒粒子中の間隙率, 架橋剤飽和度}

造粒時間 $t_{\mathrm{a}}=60 \mathrm{~min}$ において擋拌を停止し, 造粒 器内の鲧濁液より造粒粒子を分離し, これを乾燥器内 へ入れて水分を蒸発させた。その後，造粒粒子を内 径 $2.75 \mathrm{~cm}$ の円筒型容器に入れてタッピングを行い, 平衡状態における造粒粒子層のかさ容積 $V$ を測定し た。 $t_{\mathrm{a}}=60 \mathrm{~min}$ では造粒粒子はほぼ球形となるた め, 粒子径分布の測定結果を使って, Lee ${ }^{12)}$ の方法に よりタッピング容器内での造粒粒子群の粒子充填率 $\phi_{\mathrm{p}}$ を算出した。

これらの測定結果より，造粒粒子中の間隙率 $\varepsilon$, 架 橋剂飽和度 $s$ を, Eqs. (1), (2) より求めた。

$$
\begin{aligned}
& \varepsilon=\frac{V \phi_{\mathrm{p}}-w / \rho_{\mathrm{p}}}{V \phi_{\mathrm{p}}} \\
& s=\frac{r}{\varepsilon /(1-\varepsilon)}
\end{aligned}
$$

ここで, $w, \rho_{\mathrm{p}}$ は, タッピング容器中の全試料粒子質 量および試料粒子密度である。

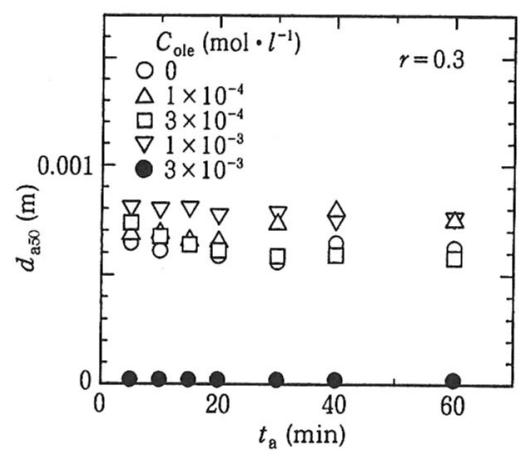

Fig. 4 Change of $d_{\mathrm{a} 50}$ of agglomerate with agglomeration time

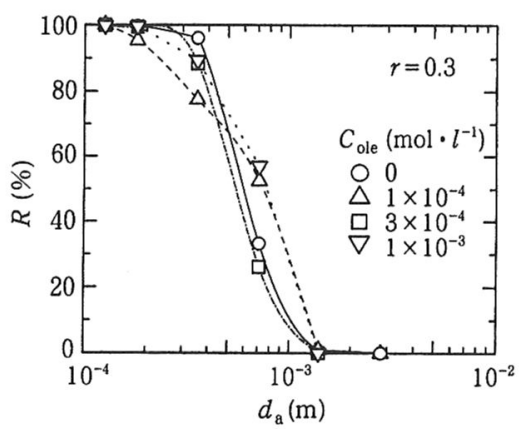

Fig. 5 Particle size distribution of agglomerates at $t_{\mathrm{a}}=60 \mathrm{~min}$

\section{3．実験結果および考察}

\section{1 湿式球形造粒への造粒条件の影響}

\section{1.1 添加界面活性剂濃度の影響}

Fig. 4 に, 架橋剤添加率 $r=0.3$ 一定の下で, 添加界 面活性剂濃度 $C_{\text {ole }}$ を変化させた時の, 質量基準の造粒 粒子の $50 \%$ 粒子径 $d_{\mathrm{a} 50}$ の経時変化を示す。図より明 らかなように，造粒現象は添加界面活性剂濃度により 大きく影響される。 $C_{\text {ole }} \leqq 0.001 \mathrm{~mol} \cdot l^{-1}$ の条件では, 全ての $r$ の条件で造粒現象は起きた。また，造粒現象 が起こる限界の $C_{\text {ole }}$ は $0.002 \mathrm{~mol} \cdot l^{-1}$ 付近に存在した が, 実験ごとに限界值は若干変動し，その值を特定 するに至らなかった。 $C_{\text {ole }} \geqq 0.003 \mathrm{~mol} \cdot l^{-1}$ の条件で は，造粒現象は起きなかった。 $C_{\text {ole }} \leqq 0.001 \mathrm{~mol} \cdot l^{-1}$ の条件では, 全ての $r$ の条件で架橋剂添加直後より造 粒現象が起こり, $t_{\mathrm{a}}=5 \mathrm{~min}$ の時点で既にペレット状 造粒粒子が形成されていた。その後 $t_{\mathrm{a}}=5 \sim 60 \mathrm{~min}$ においては， $d_{\mathrm{a} 50}$ はほぼ一定となった。これより，本 研究の最長造粒時間 $t_{\mathrm{a}}=60 \mathrm{~min}$ における $d_{\mathrm{a} 50}$ を平衡 造粒粒子径 $d_{\mathrm{ae}}$ として, 以後の検討を行った。 

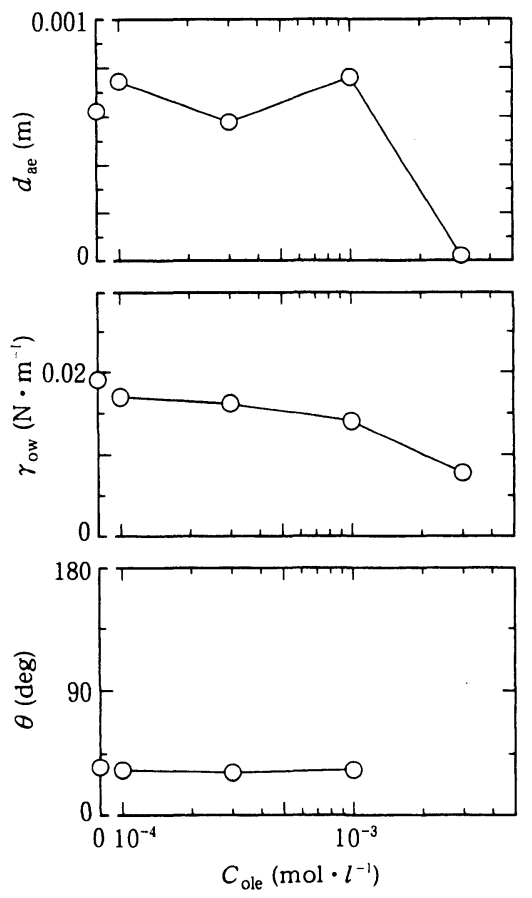

Fig. 6 Changes of $d_{\text {ae }}, \gamma_{\text {ow }}$ and $\theta$ with the change of $C_{\text {ole }}$ at $r=0.3$

Fig.5は，Fig. 4 において造粒が起こる条件での, $t_{\mathrm{a}}=60 \mathrm{~min}$ における造粒粒子の粒子径分布を示した ものである。添加界面活性剤濃度の違いによる粒子径 分布の違いは，ほとんど見られなかった。

Fig. 6 は, Fig. 4 の結果から得られた $d_{\mathrm{ae}}$ 之, 各 $d_{\mathrm{ae}}$ が得られた時の架橋剂/分散媒間の界面張力 $\gamma_{\mathrm{ow}}$, 分 散媒中における架橋剂の試料粒子表面への接触角 $\theta$ の 測定結果を示したものである。 $\gamma_{\text {ow }}$ は， $C_{\text {ole }}$ の增大と ともに減少するが, 造粒現象が起きない $C_{\text {ole }}=0.003$ $\mathrm{mol} \cdot l^{-1}$ の条件においても, $0.008 \mathrm{~N} \cdot \mathrm{m}^{-1}$ という值を 示した。一方, $\theta$ は, 造粒現象が起こる $C_{\text {ole }} \leqq 0.001$ $\mathrm{mol} \cdot l^{-1}$ の条件では, $31^{\circ} \sim 35^{\circ}$ の範囲のほぼ一定 值を示した。ただし, 図上のプロット点は 10 個の測 定値の平均値であり, 各測定値は平均值 $\pm 10^{\circ}$ 程度 の範囲内でばらついた。この原因として, 本研究では $\theta$ を造粒粒子中の液体架橋部の直接観察から測定して おり, このため造粒操作中の個々の試料粒子表面の架 橋剂による需れの履歴の違いが, $\theta$ の測定值に影響し ていることが考えられる。 $C_{\mathrm{ole}}=0.003 \mathrm{~mol} \cdot l^{-1}$ では, 試料粒子への架橋剂の付着が見られず，このため造粒 現象は起きなかった。通常, 接触角の大きさは, 液滴 の付着に関係する界面の界面エネルギーの釣り合いか ら説明される。しかし, 界面活性剂の吸着が起こる状

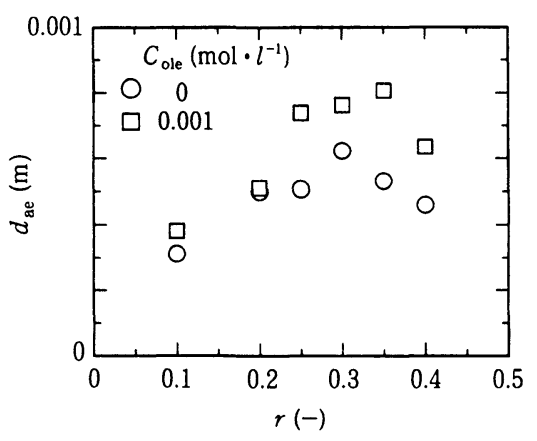

Fig. 7 Effect of $r$ on $d_{\text {ae }}$

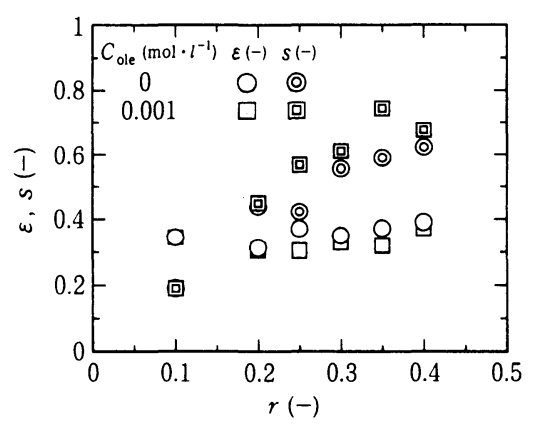

Fig. 8 Changes of $\varepsilon$ and $s$ with the change of $r$

況下では, 一方が固体面の場合の界面張力の測定は困 難である。このため, $C_{\text {ole }}=0.003 \mathrm{~mol} \cdot l^{-1}$ で架橋剂が 試料粒子に付着しないことの原因については明らかで はない。 $\theta$ は, 架橋剤添加率 $r$ の違いによりほとんど 影響されなかった。

\section{1.2 架橋剂添加率の影響}

Fig. 7 に, 平衡造粒粒子径 $d_{\mathrm{ae}}$ への架橋剂添加率 $r$ の影響を示す。 $r$ を増大させると, 最初はそれにつれ て $d_{\mathrm{ae}}$ も増大するが, $r=0.3 \sim 0.35$ で $d_{\mathrm{ae}}$ は最大值を 示し，それ以上の $r$ では $d_{\mathrm{ae}}$ は逆に減少した。Fig. 8 に, この時の造粒粒子内の間隙率 $\varepsilon$, 架橋剂の飽和度 $s$ の測定結果を示す。間隙率 $\varepsilon$ は $0.31 \sim 0.40$ の值とな った。この値より, 造粒粒子内の試料粒子の集合状態 は, ランダム密充坥に近い状態と言える。一方, 架橋 剂飽和度 $s$ は $0.19 \sim 0.74$ となり, 多くの場合, 造粒 粒子内の架橋剂はファニキュラー状態で存在している と考えられる。3.2で述べるように， $\varepsilon, s$ はともに 造粒粒子内での毛管吸引压に影響を与え, 毛管吸引厌 は $s(1-\varepsilon) / \varepsilon$ の值とともに増大する。Fig. 8の結果よ り $s(1-\varepsilon) / \varepsilon$ の值を求めると, $s(1-\varepsilon) / \varepsilon$ は $r=0.3 \sim$ 0.35 で極大值をとるような変化を示すことがわか 
る。すなわち, Fig. 7中の $d_{\mathrm{ae}}$ の変化は, 造粒粒子内 に衝く毛管吸引压の変化に対応していると考えられ る。

\section{2 平衡造粒粒子径の検討}

平衡造粒粒子径は, 造粒粒子の保形力である造粒粒 子内に働く凝集力 $F_{\mathrm{c}}$ と擋拌による破壊力 $F_{\mathrm{d}}$ が釣り 合った状態での粒子径であるといえる ${ }^{5)}$ 。

湿式球形造粒では, 凝集力 $F_{\mathrm{c}}$ は主に架橋剤の液体 架橋による毛管吸引压によるものである。本研究で は, Newitt ら ${ }^{10)}$, 久保田ら ${ }^{13)}$ の結果をもとに造粒粒 子内に㗢く凝集力 $F_{\mathrm{c}}$ を Eq. (3) で表した。

$$
\begin{aligned}
F_{\mathrm{c}} & =k_{1} s P_{\mathrm{c}} d_{\mathrm{ae}}^{2} \\
& =k_{1} s p P_{\mathrm{e}} d_{\mathrm{ae}}^{2}
\end{aligned}
$$

ここで, $k_{1}$ は定数, $P_{\mathrm{c}}, P_{\mathrm{e}}$ はそれぞれ毛管吸引圧, 入口吸引压である。 $p$ は， $P_{\mathrm{e}}$ から $P_{\mathrm{c}}$ を算出するため の係数で, 造粒粒子内の架橋剂飽和度 $s$ の関数とな る。入口吸引压 $P_{\mathrm{e}}$ は $\mathrm{Eq} .(4)$ で表される。

$$
P_{\mathrm{e}}=6 \frac{1-\varepsilon}{\varepsilon} \frac{\gamma_{\mathrm{ow}} \cos \theta}{d_{\mathrm{ps}}}
$$

ここで， $d_{\mathrm{ps}}$ は試料粒子の比表面積球相当径である。

一方，造粒粒子に対する破壊力 $F_{\mathrm{d}}$ は，主に擋拌に 伴う造粒粒子同士の衝突, あるいは造粒粒子と擋拌 翼, 造粒器壁との衝突の際に㗢く慣性力に起因するも のと考えられる。慣性力は質量 $\times$ 加速度で表される が, 上記の各衝突で作用する加速度を個別に求めるこ とは困難である。また, 本研究内では, 平衡造粒粒子 径に近い状態での造粒粒子密度は, 造粒条件によらず ほぼ等しくなる。これらのことから, 本研究では, 造 粒粒子に対する破壊力 $F_{\mathrm{d}}$ を Eq.（5）で表すことにし た。

$$
F_{\mathrm{d}}=k_{2}\left(d_{\mathrm{ae}}^{3}\right)^{\mathrm{n}}
$$

ここで, $k_{2}$ は定数であり, $n$ は破壊力への慣性力の 作用の仕方を表わすためのべき数である。

平衡造粒粒子径 $d_{\mathrm{ae}}$ は, $F_{\mathrm{d}}=F_{\mathrm{c}}$ の条件における造 粒粒子径であるから， $d_{\text {ae }}$ はEq. (6) で表される。

$$
d_{\mathrm{ae}}=\left(\frac{k_{1}}{k_{2}}\right)^{\frac{1}{3 \mathrm{n}}}\left(s p P_{\mathrm{e}} d_{\mathrm{ae}}^{2}\right)^{\frac{1}{3 \mathrm{n}}}
$$

Fig. 9 に $d_{\mathrm{ae}}$ と $s p P_{\mathrm{e}} d_{\mathrm{ae}}^{2}$ との関係を示す。図より 明らかなように, $d_{\mathrm{ae}}$ と $s p P_{\mathrm{e}} d_{\mathrm{ae}}^{2}$ との関係は, 最小二 乗法により求められた相関式Eq. (7) により良く相関 される。

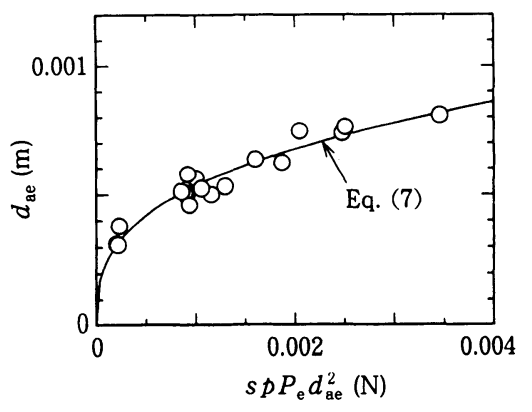

Fig. 9 Relationship between $d_{\mathrm{ae}}$ and $s p P_{\mathrm{e}} d_{\mathrm{ae}}^{2}$

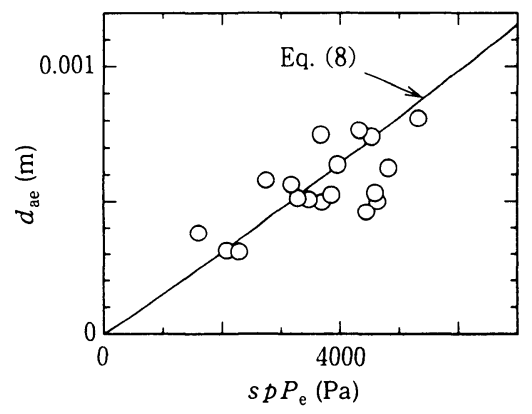

Fig. 10 Relationship between $d_{\mathrm{ae}}$ and $s p P_{\mathrm{e}}$

$$
d_{\mathrm{ae}}=5.7 \times 10^{-3}\left(s p P_{\mathrm{e}} d_{\text {ae }}^{2}\right)^{0.34}
$$

この結果は, 本研究のような摚拌速度一定の条件下で は, 平衡造粒粒子径が造粒粒子の断面全体に㗢く凝集 力に応じて決定されることを示している。Eq. (7) よ り, Eqs. (5), (6) 中のべき数部の $n$ の值は 0.98 とな る。この結果と Eq. (5) より, 衝突などによる造粒粒 子の破壊の際には, 生ずる慣性力にほぼ比例して破壊 力が増大することが考えられる。

Eq. (7) より, 平衡造粒粒子径 $d_{\text {ae }}$ と造粒粒子内の 単位断面積当りに働く毛管吸引力 $s p P_{\mathrm{e}}$ との関係は, Eq. (8) で表される。

$$
d_{\mathrm{ae}}=9.7 \times 10^{-8}\left(s p P_{\mathrm{e}}\right)^{1.06}
$$

Eq. (8) より, $d_{\mathrm{ae}}$ は, $s p P_{\mathrm{e}}$ が大きくなるにつれて比 例に近い関係で増大することがわかる。各造粒実験に おいては, 造粒粒子内の間隙率 $\varepsilon$, 架橋剂飽和度 $s$, 界面張力 $\gamma_{\text {ow }}$, 接触角 $\theta$ が, 同時に変化する。このた め, これらの値の $d_{\mathrm{ae}}$ の影響を個別に検討することは 困難であるが, $s p P_{\mathrm{e}}$ の值はそれら全ての変化の影響 を含んだものといえる。Fig. $10 に ， d_{\text {ae }}$ の測定值を $s p P_{\mathrm{e}}$ に対してプロットした図を示す。 


\section{4. 結 言}

球形試料粒子を用い, 添加界面活性剂濃度, 架橋剂 添加率を変えて湿式球形造粒を行い, 得られる平衡造 粒粒子径について検討した。その結果，以下のことが 明らかとなった。

1 ）分散媒中への添加界面活性剂濃度の増大は, 架橋 剂／分散媒間の界面張力を減少させ，架橋剂の試 料粒子表面への接触角にも影響を与えた。一定の 添加界面活性剤濃度以上で試料粒子表面への架橋
剂の付着が起こらなくなり，このとき造粒現象は 起きなくなった。

2 ) 平衡造粒粒子径は, 造粒粒子内の間隙率之架橋剂 飽和度の変化により大きく影響された。

3 ）毛管吸引圧により造粒粒子内に㗢く凝集力と, 擋 拌による破壊力の釣り合いから平衡造粒粒子径が 決まるというモデルにより, 平衡造粒粒子径の測 定值と湿式球形造粒に影響する各種要因との関係 がよく説明された。

\section{Nomenclature}

$C_{\text {oke }}:$ concentration of added sodium oleate

$d_{\mathrm{a}}$ : agglomerate diameter

$d_{\text {ic }}$ : equilibrium agglomerate diameter

$d_{\mathrm{i} \tilde{5} 0)}: 50 \%$ diameter of agglomerate

$d_{1}$ : diameter of raw particle

$d_{p s}$ : specific surface diameter of raw particle

$d_{1, \bar{x})}: 50 \%$ diameter of raw particle

$F_{\mathrm{c}}$ : cohesive force

$F_{\mathrm{d}}$ : destructive force

$k_{1}$ : constant in Eq. (3)

$k_{2}$ : constant in Eq. (5)

$n$ : power exponent in Eq. (5)

$P_{c}$ : capillary suction potential

$P_{\mathrm{c}}$ : entry suction potential

$p$ : coefficient in Eq. (3)
$R$ : cumulative oversize percent

(\%)

$(-)$

$\left(\mathrm{mol} \cdot \mathrm{1}^{-1}\right)$

(m)

(m)

(m)

(m)

(m)

(m)

(N)

(N)

$(-)$

$\left(\mathrm{N} \cdot \mathrm{m}^{-3 n}\right)$

$(-)$

(Pa)

$(\mathrm{Pa})$

$(-)$

$r$ : addition ratio of bridging liquid

$(-)$

$t_{\mathrm{a}} \quad$ : agglomeration time

$V$ : apparent volume of packed agglomerates bed

(min)

$\left(\mathrm{m}^{3}\right)$

$w$ : mass of raw particle in agglomerates $(\mathrm{kg})$

$\gamma_{\text {ow }}:$ interfacial tension of castor oil/disperse medium system

$\left(\mathrm{N} \cdot \mathrm{m}^{-1}\right)$

$\varepsilon \quad$ : porosity in agglomerate (-)

$\theta$ : contact angle $\left({ }^{\circ}\right)$

$\mu_{\mathrm{o}}:$ viscosity of castor oil (Pa $\left.\cdot \mathrm{s}\right)$

$\rho_{\mathrm{o}}:$ density of castor oil $\quad\left(\mathrm{kg} \cdot \mathrm{m}^{-3}\right)$

$\rho_{\mathrm{p}}$ : density of raw particle $\left(\mathrm{kg} \cdot \mathrm{m}^{-3}\right)$

$\phi_{\mathrm{p}}$ : packing volume fraction of agglomerates (-)

\section{References}

1) Sakamoto, H. and J. Shimoiizaka : "Agglomeration of Pyrite in Aqueous Suspension”, J. Min. Metal. Inst. Japan, 94, 805-808 (1978)

2) Takase, H. and M. Sugimoto: "Study on Deashing of Coal by the Oil Agglomeration Process-Influence of Growth of Agglomerates and Washing on Deashing Efficiency-", J. Soc. Powder Technol., Japan, 26, 552557 (1989)

3 ) Takase, H., K. Higashi and M. Sugimoto: "Study on the Deashing of Coal by the Oil Agglomeration Process-The Effect of Ground Coal Particle Size on Deashing Efficiency-", J. Soc. Powder Technol., Japan, 28, 430-436 (1991)

4 ) Takase, H. and M. Sugimoto: "Influence of Agglomerate Size on Drainage of Packed Bed of Coal Agglomerates”, Kagaku Kogaku Ronbunshu, 15, 238-245 (1989)

5 ) Capes, C. E. and J. P. Sutherland: "Formation of Spheres from Finely Divided Solids in Liquid Suspension", Ind. Eng. Chem., Process Design and Develop., 6, 146-154 (1967)

6 ) Takenaka, H., Y. Kawashima, M. Nakashima and Y.
Kurachi: "Interfacial Chemical Properties of Powder and Spherical Agglomeration in Liquid", J. Soc. Powder Technol., Japan, 16, 681-686 (1979)

7 ) Kawashima, Y., K. Furukawa and H. Takenaka : "The Physicochemical Parameters Determining the Size of Agglomerate Prepared by the Wet Spherical Agglomeration Technique", Powder Technology, 30, 211-216 (1981)

8 ) Kawashima, Y., K. Niwa, H. Takeuchi, T. Hino and T. Niwa : "Effects of Amount of Bridging Liquid on the Growth Process and the Compaction Process of Agglomerate in Wet Spherical Agglomeration", Yakugaku Zasshi, 110, 591-597 (1990)

9 ) Hirajima, T., T. Takamori, M. Tsunekawa and M. Tsurui: "Studies of the Surface Properties of a Particle-Water-Oil System and Their Relationship to the Agglomerate Formation in a Liquid”, J. Soc. Powder Technol., Japan, 24, 771-776 (1987)

10) Newitt, D. M. and J. M. Conway-Jones: "A Contribution to the Theory and Practice of Granulation", Trans. Instn. Chem. Engrs., 36, 422-442 (1958)

11) Nippon Kagakukai : "Shin Jikken Kagaku Kouza 18”, 
pp. 78-79, Maruzen, Tokyo (1977)

12) Lee, D. I. : "Packing of Spheres and Its Effect on the Viscosity of Suspensions", J. Paint Technol., 42, 579587 (1970)
13) Kubota, N., T. Kawakami and S. Ohtani: "A Dimensionless Group for the Capillary Suction Pressure", Kagaku Kogaku, 32, 822-824 (1968) 